\title{
Correspondence
}

\section{Medical abdicationism}

DeAR SiR,

May I be allowed to comment on Dr Walk's letter (Bulletin, February 1982, 6, 34). It is an unpalatable fact that doctors have no control on the qualifications and administrative movements of nursing staff. Yes, at the moment medical abdicationism in psychiatry is widespread and has been dictated not by medical failure or laissez-faire but by excessive alteration of relations with other disciplines. The pyramid of decision-making has become so flattened as to be actually inverted, i.e., people at the periphery who carry no responsibility have assumed authority. It is strange and absurd that those same people should still critically attribute ultimate responsibility and accountability to the consultant.

I have no nostalgia for the medical superintendent regime. We have painfully enriched our experience and considerably helped our patients by coming down to earth, but there is a limit beyond which the concepts 'doctor', 'patient', 'nurse', 'treatment' cannot be stretched.

Perhaps, change has gone too far on its own momentum and one can only hope that a series of publicized absurdities and contradictions, such as the one in Dr Walk's letter, will help the inverted pyramid to rebound.

Prestwich Hospital

Manchester

\section{Treating the Troublesome}

\section{DeAR SIR}

I wonder if you would allow me a comment or two on $\mathrm{Dr}$ John Hamilton's review (Bulletin, March 1982, 6, 47). From what Dr Hamilton says it is obvious that the term 'patient's advocate' has come to symbolize some kind of antimedicine, as though patients' advocates would be opposed to good medical care. Yet this is not the case. The concept originates in ordinary medical practice. If a patient is advised to have, say, an operation he needs both medical and personal advice before coming to lay judgment whether to accept that advice or not. In this century strenuous attempts have been made in Britain to bring psychiatric treatment as close to this model as possible and even compulsory care under the Mental Health Act incorporates a lay elementeither the closest relative or a social worker.

What is being suggested in Treating the Troublesome 1 is that these principles should be brought into the second stage of compulsory care if necessary. Some patients already in hospital under compulsion may, in their doctor's opinion, require compulsory treatment as well, perhaps medication or
ECT. Treating the Troublesome suggests that it ought to be accepted that in these circumstances it is good medical practice (other than in cases of emergency) to get other medical opinion and discuss the matter with the patient's relatives, friends or advisers, before proceeding with the compulsory treatment. However, the pamphlet specifically sets its face against changes in the law to compel doctors to practise this way, it goes so far as to say 'the best long-term guarantee of ... safeguards lies in confiding them to independent members of independent health professions, neither individually nor collectively subject to direction (or, as far as possible, even influence) by potentially authoritarian state institutions, and reinforced by professional ethics, and ultimately by the law'. The law it refers to is the current civil law. In other words the pamphlet is advocating a conservative and educational approach to this problem within the legal framework which already exists.

It is impossible in a short letter to discuss the reasons why all of us, doctors, lawyers, philosophers, and lay people, on the CSS Working Party approved of the lay element in all medical decisions, including compulsory ones (even though we felt the current law to be perfectly adequate in this respect) but if anybody is interested in a lucid analysis of the arguments I would recommend Dr Raanan Gillon's John Locke Lecture published in the Christmas edition of the BMJ. ${ }^{2}$ JoHN GunN

Institute of Psychiatry

London SES

REFERENCES
'COUNCIL FOR SCIENCE AND SOCIETY (1981) Treating the Troublesome. London: CSS.

${ }^{2}$ Gillon, R. (1981) The function of criticism. British Medical Journal, 283, 1633-39.

\section{Mental Health Act Commission}

DeAr Sir,

May I offer some criticisms relating to the Mental Health Act Commission proposed in the Bill now before Parliament.

The remit of the MHAC may be construed to relate only to individuals. The MHAC is concerned with detained patients and it is envisaged that it will not examine the general conditions in hospital; this task will continue to be dealt with by the Health Advisory Service and National Development Teams. Yet many issues which have a crucial effect on the experience of patients relate to hospital conditions and regulations, and do not lend themselves to consideration from an individualistic perspective. The total separation of the Health Advisory Service and the National Development Teams from the MHAC appears artificial and inimical to the overall raising of standards in the interests of 